\title{
SHOULDER AND CENTER LINE RUMBLE STRIPS: REDUCING SEVERITY OF ROAD CRASHES IN INDIA
}

\author{
Amit Vashisth ${ }^{1}$ \\ ${ }^{1}$ Panipat Institute of Engineering and Technology, Panipat, India
}

Received 1 September 2017; accepted 28 March 2018

\begin{abstract}
In India, road accident is one of the major factors responsible for most deaths. Every Year almost 0.15 million people die on Indian roads every year and the major factor responsible is human errors that account for almost $80 \%$ of the accidents and these human errors are the results of engineering defects in $70 \%-80 \%$ cases. These human errors could be asleep, fatigue, inattentiveness, Distraction etc that led to road or lane departure. Shoulder rumble strips (SRS) and center line rumble strips (CLRS) are the techniques that could be proved a milestone in making our roads more favorable to drive and more forgiving. We observed that there is no such measure taken on Indian roads which can alert road user before losing their lane. SRS and CLRS somehow alert road users by shaking vehicle and making a loud noise so as to avoid off - road crashes. These two techniques come under the category of lane departure warning system. Location of these techniques can be identified by black spot data for the country. Indian road users could be benefited from this technique of making roads more alerting and forgiving so as to reduce the accidents by compensating human errors.
\end{abstract}

Keywords: asleep, fatigue, inattentiveness, distraction, lane departure, rumble strips.

\section{Introduction}

Accidents on Indian roads are becoming more severe year by year. During 2015, a total of more than 0.5 million road accidents were reported in India. In these accidents $26.3 \%$ were fatal. The number of persons killed in road accidents were almost 0.15 million. The number of road accidents, fatalities and persons injured and severity in road accidents in India during 2005 to 2015 as represented by (Mitra and Saxena, 2015) in the accident report 2015 released by Government of India, Ministry of Road Transport and Highways (MORTH), Transport research wing are shown in Table 1. SRS and CLRS are the techniques to reduce the severity of accidents by warning drivers before hitting the road furniture or any other vehicle or pedestrian. SRS and CLRS basically reduce severity of run-off-road and centerline crashes on roads. Lot of work has been done yet in this direction; some of the studies are discussed here in literature review.

${ }^{1}$ Corresponding author: amitvashisth.civil@piet.co.in 
Table 1

Accident Data for India (2005-2015)

\begin{tabular}{|l|l|l|l|l|l|}
\hline Year & Total & Fatal (\%) & Person killed & Person injured & $\begin{array}{l}\text { Severity(no. Of person } \\
\text { killed/100 accidents) }\end{array}$ \\
\hline 2005 & $4,39,255$ & 19.0 & 94,668 & 465282 & 21.6 \\
\hline 2006 & $4,60,920$ & 20.4 & 105,749 & 496481 & 22.9 \\
\hline 2007 & $4,79,216$ & 21.1 & 114,444 & 513340 & 23.9 \\
\hline 2008 & $4,84,704$ & 22.0 & 119,860 & 523193 & 24.7 \\
\hline 2009 & $4,86,384$ & 22.8 & 125,660 & 515458 & 25.8 \\
\hline 2010 & $4,99,628$ & 23.9 & 134,513 & 527512 & 26.9 \\
\hline 2011 & $4,97,686$ & 24.4 & $1,42,485$ & 511394 & 28.6 \\
\hline 2012 & $4,90,383$ & 25.1 & $1,38,258$ & 509667 & 28.2 \\
\hline 2013 & $4,86,476$ & 25.2 & $1,37,572$ & 494893 & 28.3 \\
\hline 2014 & $4,89,400$ & 25.7 & $1,39,671$ & 493474 & 28.5 \\
\hline 2015 & $5,01,423$ & 26.3 & $1,46,133$ & 500279 & 29.1 \\
\hline
\end{tabular}

Source: Source: (Mitra and Saxena, 2015)

\section{Literature Review}

Troughton and Waldock (2013) Main roads Australia in an annual report of the regional Run-off-Road (ROR) program suggest that Single Vehicle run-off-road (SVROR) crashes accounts for $60 \%$ of all road deaths and injuries in regional and remote Western Australia from 2008-2012. (Ligon et al., 1985) revealed in a research that $19.8 \%$ accidents reduced at the test site with SRS which was analyzed through chi-squared analysis on before and after studies. (Cheng et al., 2000) done before and after analysis of crash data in 1992-1993 on Utah roadways and conclude that expressways without SRS experience more ROR crashes i.e. $33.4 \%$ as compared to $26.9 \%$ with SRS. Also from this study, it was found that segments with asphalt SRS installed near travel lane result in lower accident rate as compare to concrete SRS. Wood (1994) done evaluate initial Sonic Nap Alert Pattern (SNAP) installed on the Pennsylvania turnpike revealed that driftoff-road (DOR) crashes reduced to $30 \%$ after installation of SRS. (Torbic, 2009) revealed $22 \%$ reduction in SVROR crashes and 51\% reduction in fatal and injury SVROR crashes but suggest more sound research to do. $\mathrm{He}$ also records $38 \%$ to $50 \%$ percent reduction in severe accidents on two-lane rural roads and two-lane urban roads revealed $37 \%$ to $91 \%$ reduction in severity on treated Center line rumble strips (CLRS). Unlike to SRS, CLRS are constructed in the center of the carriageway and act as a divider so as to alert the driver from drifting into the opposite lane as shown in Figure 2. (Olson et al., 2011) Performance Analysis of CLRS in Washington State in 2011 found that CLRS act as the counter measure for crosscenter line crashes led to $44.76 \%$ reduction in injury severities and $48 \%$ reduction in fatal and serious injuries crashes. (Russell et al., 2003) found $15 \%$ reduction in overall crashes and $15 \%$ reduction in injury crashes and $21 \%$ reduction in head-on-collision and $25 \%$ reduction in head-on and sideswipe. In a Japanese study, (Hirasawa et al., 2005) evaluated $111.9 \mathrm{~km}$ of existing CLRS installations and noted $55.2 \%$ reduction in head-on collisions. (Spainhour and Mishra, 2008) observed that drivers were $50 \%$ times more alert on roads with rumble strips. 


\section{Methodology}

SRS and CLRS are the techniques to reduce the severity of accidents by warning drivers before hitting the road furniture or any other vehicle or pedestrian. SRS and CLRS basically reduce severity of run-offroad and centerline crashes on roads. The objective of the present study is identify the factors responsible and circumstances in which drivers make faults which lead to ROR crashes on Indian highways as driver's fault is directly or indirectly related to ROR Crashes. The objective of the study is:

- To introduce the technique of SRS and CLRS in India as a solution to reduce severity of road crashes in India;

- To get overview of Design technique for SRS and CLRS;

- To find the potential location for placement of SRS and CLRS with the help of data on "Black spots" in India;

- To motivate professionals, research scholars, and students to study the viability, feasibility and effectiveness of shoulder and center line rumble strips in India;

- To motivate responsible Indian authorities to introduce its own standard design code for SRS and CLRS as per Indian conditions.

\section{Factors Affecting Run-off and Other Road Crashes on Indian Roads}

(Mitra and Saxena, 2015) revealed that drivers' fault is the most important factor responsible for accidents in India which accounts for $77.1 \%$ of total road accidents, almost $62 \%$ of the accidents are due to not following laws, and almost $4 \%$ of accidents are due to drink and drive on highways. We try to put emphasis on exactly what could be the circumstances in which drivers make mistakes and contribute towards $77 \%$ of the accidents on Indian roads.

We try to identify various circumstances and factors responsible for drivers' fault on Indian roads, with help of format specified by Indian Roads Congress (IRC) for road accident reporting i.e. IRC: 53-1982 form A1 and 4 and with our own experience as shown in Table 2 . These driver faults are directly or indirectly responsible for ROR crashes and need to be addressed very seriously. In this direction, SRS and CLRS would be the desired technique to make Indian roads more "Forgiving" and "Self Explanatory". What we need is to apply these measures to Indian roads so that overall reduction in accidents and their severity could be done.

Table 2

Contributing Factors for Drivers' Fault

\begin{tabular}{|c|l|}
\hline Contributing Factors & \multicolumn{1}{c|}{ Contributing Circumstances } \\
\hline Asleep/Fatigued & Apparently Asleep or Fatigued or Sick \\
\hline Inattentive/Distracted & $\begin{array}{l}\text { Inattention or attention diverted of the driver at the moment due to: } \\
\text { Eating or Drinking, Interacting with Passengers present in the Vehicle, } \\
\text { Operating Electronic and Communication Device, Reading or Writing, } \\
\text { Smoking, Other Distractions Inside and outside the Vehicle }\end{array}$ \\
\hline Under Influence & Under Influence of Alcohol, Drugs or medicine \\
\hline Speed & Exceeding Lawful or Safe Speed \\
\hline Over Centerline & Over Centerline, On the Wrong Side of Road \\
\hline
\end{tabular}




\section{Techniques to Reduce Run-Off Road Crashes and Severity of Accidents}

It is our primary safety goal to reduce severity and number of highways departure crashes, these could be run-off-road (ROR) and centerline crashes. Major safety initiatives planned to achieve these goals includes keeping vehicles on the roadway and improving safe recovery after distraction on roadways and to reduce severity due to the distraction of the drivers. Shoulder rumble strips (SRS) are used to prevent ROR crashes by warning drivers and making them aware that their vehicle is drifting onto the road side. Rumble strips are introduced as a counter acting measure to the drivers' fault rather than defects in roadway design. They are designed primarily to avoid and recover from distraction and inattentiveness such as drowsiness, fatigue or drink and drive due to which are intentionally or unintentionally responsible for ROR crashes on highways. For this type of driving, audible and vibratory warning must be introduced on roadsides which can improve safe recovery from distraction for the driver. A drift-off accident, caused by sluggish, occupied, or generally heedless driving, is a subset of ROR crashes. Milled rumble strips proved to be most effective countermeasures in most of the cases. They confront risk factors such as ROR injury crashes, Driftoff-road crashes and to mitigate these factors, producing noise and vibration in a vehicle which leads to a higher crash reduction by alerting drivers. SRS is a low cost and highly effective technique to reduce SVROR crashes and its severity. These can be installed on freeways, expressways, national highways and other divided highways. These rumble strips are made outside of the highways as shown in Figure 1. On the other hand, CLRS can prevent head on collision and opposite side swipes on undivided highways. CLRS is the demonstrated remedy that lessens the dangers of center line crossing crashes. CLRS are put as a counteragent for driver's mistake, as opposed to roadway inadequacies. They are planned basically to help diverted or generally distracted drivers who accidentally roam over the center line. In this case CLRS alert drivers by vibration and noise which help them to stay in their lane which leads to reduced center line crashes.

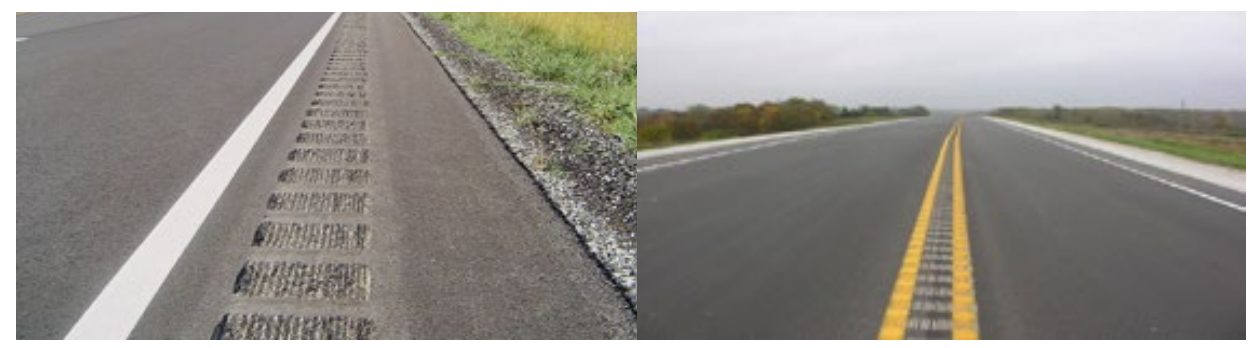

Fig. 1.

SRS (left), CLRS (right)

Challenges: (Higgins and Barbel, 1984) performed research on vibration and noise produced by SRS and CLRS and found that these rumble strips produced additional $7 \mathrm{db}$ low-frequency noise level as compared to normal traffic. It may be undesirable to the surrounding environment, for example, nearby residents or business complexes. Careful attention in design can result in less loud noises. 


\section{Design Criteria for SRS and CLRS}

Widely used Rumble strips are Milled-in rumble strips (refer Fig. 1), Raised and Rolled-in rumble strips (refer Fig. 2) and
Formed rumble strips. (Perrillo, 1998) analyzes that ROR crashes on rural interstate and pathways with milled SRS reduced by $65 \%$. Typically, milled rumble strips are used as CLRS.

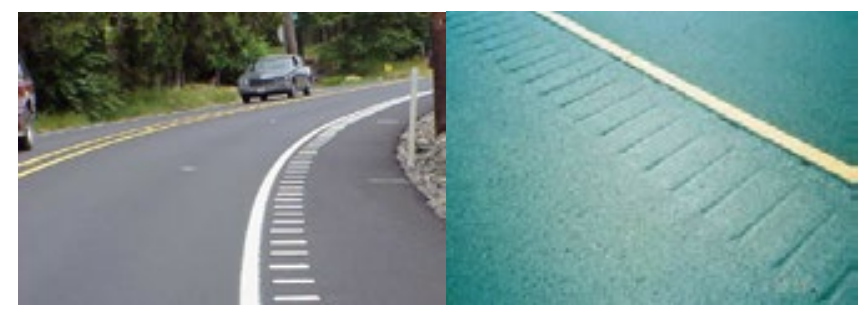

Fig.2.

Raised (Left) and Rolled-in (right) Rumble Strips

Dimensions: Dimensions will be same for both types i.e. SRS and CLRS. Optimum dimensions for SRS and CLRS depend on the condition of operations, the crosssection of the carriageway, and possible road users. Depression (D) and width (C) of the strip are the major measurements that have a considerable impact on the sound and vibration. Other dimensions such as distance from the edge line (A), the length of the strip (B) and spacing between two rumble strips (E) are there, as shown in Fig. 3. CLRS may have less depth as compare to SRS to produce same audible and vibratory warning for the driver because at the critical driver position more noise is produced than from another side. It is to be noted that exact dimensional values i.e. A, B, C, D, and $\mathrm{E}$ are not discussed here and can be specified as per Indian conditions.

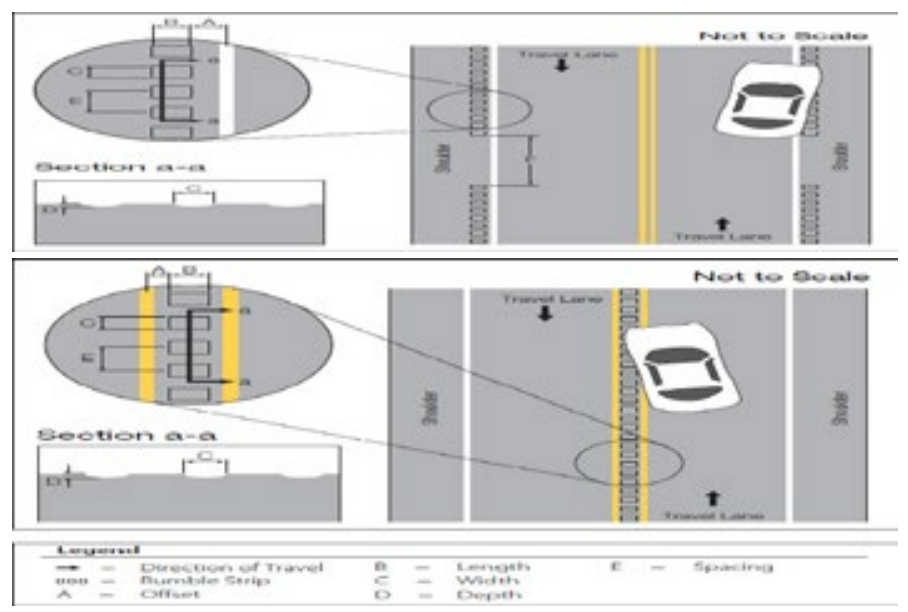

Fig. 3.

Design of SRS (up), CLRS (down)

Source: (Federal Highway Administration, 2011) 


\section{Potential Locations for Installation of SRS and CLRS in India}

Ministry of Road Transport and Highways (MORTH), Road safety Cell (Engineering) identified more than 750 black spots on national highways across the country in the report (Black spots on national highways, 2015). As per the definition by MORTH, more than ten accidents on a location with maximum $1 \mathrm{~km}$ road length will be classified as a black spot. Location of black spots will lead to identifying proposed location for the installation of SRS and CLRS where ROR crashes are maximum. Installation of these techniques could be on a priority basis and as a test project for future studies. These black spots are categorized on the basis of priority (refer Table 3) and black spots on top 10 national highways are shown in Table 4.

Table 3

Classification on the Basis of Priority

\begin{tabular}{|c|c|c|}
\hline Priority & Total Fatalities(2011-2013) & No. of Black Spots \\
\hline Priority 1 & $>95$ & 18 \\
\hline Priority 2 & $70-95$ & 19 \\
\hline Priority 3 & $45-69$ & 32 \\
\hline Priority 4 & $21-44$ & 154 \\
\hline Priority 5 & $<21$ & 495 \\
\hline Special Priority & - & 7 \\
\hline
\end{tabular}

Source: (Mitra and Saxena, 2015)

Table 4

Number of Black Spots on Top Priority National Highways

\begin{tabular}{|c|c|}
\hline National Highway & No. of Black Spots \\
\hline NH-2 (Delhi- Kolkata) & 59 \\
\hline NH-8 (Delhi - Mumbai) & 45 \\
\hline NH-44 (Nongstoin - Sabroom) & 38 \\
\hline NH-4 (Thane - Chennai) & 27 \\
\hline NH-45 (Chennai - Teni) & 24 \\
\hline NH-47 (Salem - Kanyakumari) & 22 \\
\hline NH-7 (Varanasi - Kanyakumari) & 22 \\
\hline NH-6 (Hajira - Kolkata) & 20 \\
\hline NH-28 (Baruani-Lucknow) & 20 \\
\hline NH-24 ( Delhi-Lucknow) & 19 \\
\hline
\end{tabular}

Source: (Mitra and Saxena, 2015)

\section{Maintenance and Mitigating Adverse Effects}

\subsection{Maintenance}

Rumble strips are generally maintained by treating with layer of asphalt and fine aggregates over a current rumble strip can hold the essential state of the rumble strips when it loses its cross section, thin blacktop (hot mixed) and micro-surface paving could be another maintenance methods for rumble strips. Chip seal stones will improve the audibility as well as vibrations produced by the rumble strips. 


\subsection{Mitigation}

Noise to nearby residents: SRS and CLRS proved to be an effective technique in reducing ROR and center-line cross crashes respectively but we can't ignore the adverse effect of noise produced by rumble strips to the heavy population resides nearby areas at some cross sections. Acceptable countermeasures must be taken to reduce disturbances produced by rumble strips so as to make such projects more viable and acceptable to the general population. Mitigation of the excess noise can be done by following:

- Offset (A) could be increased, where offtracking is common and inroad stretches with heavy traffic to avoid unbearable noise;

- Removal of the rumbles may be done in the region where disapproval overcome benefits of SRS and CLRS utilization;

- Modification of different measurements of the rumble strip such as width, depth, and gap between consecutive rumble strips allowed by local conditions may be done.

\section{Conclusion and Recommendation}

Through rigorous literature review for SRS and CLRS, we observed that these techniques have been efficient and working for almost 50 years in western countries to reduce ROR crashes and center-line-cross crashes. These techniques may not avoid an accident but its severity can be avoided by alerting road users before they cross the edge of the road or cross their lane on highways with no dividers. There is no doubt that currently maximum number of accidents are recorded as drivers' fault but the question is how long we keep on saying that driver itself is responsible for most of the accidents. As a human we always make mistake and expect to be "forgiven" but in the context of road accidents none of the road users is forgiven and results in severe accidents. As engineers, it is our moral responsibility to facilitate road users in such a way that they could be alerted before any causality on the road, and SRS and CLRS techniques are big leaps in this direction. Some of the Recommendations are as follows:

- During data collection of accidents, a team of experts must work along with the police personnel so that more specific reason of the accident can be identified;

- Identification of types and reason of crashes whether it is on-road or off-road must be done as there is no specific data on run-off-road crashes is present in accident study on Indian roads;

- Circumstances in which driver makes mistakes on roads which lead to a crossing of respective lanes must be identified for more specific accident data;

- Highway professionals and researchers must come forward to implement this type of project primarily on potential locations as a test and further research can be done on feasibility and effectiveness of SRS and CLRS in India;

- Higher authorities such as Ministry of Road Transport and Highways (MORTH) and Indian Roads Congress (IRC) must initiate this type of project and after rigorous research, codes can be modified for rumble strips and standard specification for the design of SRS and CLRS can be added in the codes as per Indian conditions. 
Limitations: It is not possible that $80 \%$ of the accidents are because of driver's fault. The major problem here in accident data is the limitations of technical knowledge of the personnel who had collected data on various locations. Police personnel collecting data are not aware of the terms such as side- swipe and run-off crashes, that is why it was not possible to get data on exact run-off-crashes on Indian roads for which SRS and CLRS are more applicable. Data observed here is for the year 2015 accident report; we observed that there is no uniform format for the country in which the data is being submitted to the authorities to make final report on accidents in India.

\section{References}

Black spots on national highways 2015. Government of India, Ministry of Road Transport and Highways, Road safety Cell (Engineering). Available from internet: $<$ http://morth.nic.in>.

Cheng, E.Y.; Gonzalez, E.; Christensen, M.O. 2001. Application and Evaluation of Rumble Strips on Highways. In Compendium of Technical Papers, $64^{\text {th }}$ ITE Annual Meeting Institute of Transportation Engineers.

Higgins, J.S.; Barbel, W. 1984. Rumble strip noise, Transportation Research Record (983).

Hirasawa, M.; Asano, M.; Saito, K. 2005. Study on development and practical use of rumble strips as a new measure for highway safety, Journal of the Eastern Asia Society for Transportation Studies 6: 3697-3712.

Ligon, C.M.; Carter, E.C.; Joost, D.B.; Wolman, W.W. 1985. Effects of shoulder textured treatments on safety. $69 \mathrm{p}$.
Mitra S.; Saxena, K. 2015. Road accidents in India, Government of India, Ministry of Road Transport and Highways, Transport research wing. Available from internet: <http://pibphoto.nic.in>.

Olson, D.; Manchas, B.; Glad, R.W.; Sujka, M. 2011. Performance Analysis of Centerline Rumble Strips in Washington State (No. WA-RD 768.1). Available from internet: <https://www.wsdot.wa.gov>.

Perrillo, K. 1998. The effectiveness and use of continuous shoulder rumble strips. Available from internet: <https://safety.fhwa.dot.gov>.

Russell, E.R.; Rys, M.J.; Brin, T.S. 2003. US experience with centerline rumble strips on two-lane roads: Pattern research and North American usage. Available from internet: <http://www.ctre.iastate.edu>.

Spainhour, L.; Mishra, A. 2008. Analysis of fatal run-offthe-road crashes involving overcorrection, Transportation Research Record: Journal of the Transportation Research Board 2069: 1-8.

Torbic, D.J. 2009. Guidance for the design and application of shoulder and centerline rumble strips. Transportation Research Board (Vol. 641).

Troughton S.; Waldock, R. 2013. Annual report 2013. Regional run-off road program, Main Roads Western Australia. Available from internet: <https:// annualreports.mainroads.wa.gov.au>.

Wood, N.E. 1994. Shoulder rumble strips: a method to alert drifting drivers. In $73^{\text {rd }}$ Annual Meeting of the Transportation Research Board, Washington, DC, 6 p. 